\title{
De la ciencia a la poesía en el mismo viaje: entrevista a Balam Rodrigo
}

\section{Flor Aguilar Manjarrez}

Balam Rodrigo (Villa de Comaltitlán, Chiapas, Centroamérica, 1974) es uno de los poetas más destacados y reconocidos de la literatura mexicana contemporánea. Exfutbolista, biólogo y diplomado en teología pastoral, entre sus libros se pueden mencionar Braille para sordos (2013), Desmemoria del rey sonámbulo (2015), El órgano inextirpable del sueño (2015), El corazón es una jaula de relámpagos (España, 2015) y Iceberg negro (2015). Poemas suyos han sido traducidos al inglés, portugués, polaco, zapoteco y francés, y aparecen en antologías, revistas y diarios de México, así como en publicaciones de República Dominicana, Brasil, Colombia, Argentina, Chile, España, Puerto Rico, Estados Unidos, Guatemala, Honduras, Portugal y Alemania. Ha merecido, entre otros reconocimientos, el Certamen Internacional de Literatura Sor Juana Inés de la Cruz 2012 y el Premio Internacional de Poesía Jaime Sabines 2014. Actualmente es miembro del Sistema Nacional de Creadores de Arte de México en la disciplina de Letras. La siguiente entrevista se realizó a propósito de la visita del poeta a UTA. (La Redacción)

\section{¿Cuándo y dónde nace Balam Rodrigo?}

Nací el 11 de octubre de 1974 en Villa de Comaltitlán, Chiapas, México, un pueblo de la región conocida como Soconusco, costeño y también montañoso, que además de tener varios ríos, se caracteriza por ser uno de los lugares más antiguos del mundo donde se cultiva cacao y produce chocolate, y además de contar con esteros y mar, tiene bosques de niebla en los que se cultiva café.

\section{¿De qué manera haber nacido en la frontera ha marcado la vida de Balam Rodrigo?}

Chiapas forma parte, sin duda alguna, de esa región del mundo llamada Centroamérica. Así, el haber vivido y pasado la infancia, la adolescencia y parte de mi juventud ligadas a la "frontera sur" de México, me dio un carácter fronterizo, lleno de diversos matices y mestizajes. Esto, debido a que la llamada "frontera sur" es más impostada que natural, totalmente porosa y casi inexistente, sin embargo, divide a 
los centroamericanos de México (los chiapanecos) y a los centroamericanos de los otros países, de manera geopolítica y con marcada xenofobia por parte de los centroamericanos de Chiapas, aunque somos la misma gente, con la misma cultura e identidad, pues compartimos los mismos rasgos y características identitarias. De este modo, poco antes de cumplir 20 años migré a la Ciudad de México para estudiar la universidad, y ahí pude darme cuenta de que los chiapanecos somos más afines y cercanos a guatemaltecos, salvadoreños y hondureños, por ejemplo, que a "los otros mexicanos". En este sentido, somos los únicos mexicanos que aún "voseamos", es decir, que utilizamos el voseo, ese particular pronombre, al hablar, y claro, también al escribir. Nuestro español, el de los chiapanecos, pertenece lingüísticamente, al español centroamericano. Pero no sólo eso compartimos los chiapanecos con los otros centroamericanos: también la miseria, las carencias, la violencia, guerrillas, la discriminación contra nuestras lenguas, etnias y pueblos originarios. Adquirir conciencia de esto, sin duda, es algo que me ha marcado mucho.

Usted dedica tiempo para impartir seminarios en hospitales sobre variados temas como la "bioética, la religión y tradiciones de la muerte en México". ¿Cuál es el objetivo de esos cursos y por qué los realiza en los hospitales?

He impartido por casi diez años los cursos "dilemas bioéticos" y "las religiones en la muerte" en diplomados de tanatología, una ciencia relativamente "nueva" relacionada con los procesos de duelo y las pérdidas, y no sólo las derivadas de la muerte de una persona, sino todo tipo de pérdidas (laborales, emocionales, físicas, etc.) que pueden transformarse en una enfermedad, toda vez que las personas no las superan. La tanatología es una herramienta imprescindible que busca que las personas estén conscientes de su finitud, de que algún día morirán, y la apropiación de la conciencia del morir, de que tenemos un tiempo limitado de vida, puede transformarse en un mejor vivir. Por otra parte, incluir el estudio de la bioética y las religiones en la tanatología (y su íntima y estrecha relación con la muerte, con lo trascendente) es reconocer su aporte humanista, ya que la primera provee de un marco ético y moral a las ciencias biológicas y de la salud, y las segundas reconocen la religiosidad y la espiritualidad como parte de los derechos y libertades fundamentales de toda persona humana, ya que le dan sentido a la vida, y por ende, a la muerte. El diplomado se imparte en hospitales debido a que mis alumnos son, en su mayoría, médicos, sicólogos, trabajadoras sociales, enfermeras, psicoterapeutas, etc., personas que trabajan en el área de la salud, y muchos de ellos, con personas en proceso de muerte o duelo.

\section{Hablemos del escritor. Balam Rodrigo es por demás un hombre polifacético, ¿En qué momento de su vida nace en usted la inquietud por la poesía?}

Desde muy temprana edad las palabras me interesaron mucho, el encantamiento que ellas generan cuando las decimos. Y apenas inicié a leer, me interesó mucho la palabra escrita, la de los libros. Cabe mencionar que la tradición oral, esa otra forma de la poesía, de lo poético, ha sido muy importante para mí. Por ejemplo, me influyeron mucho los cuentos, leyendas y mitos que me contaba mi padre en la infancia, 
así como las canciones populares, dichos, refranes, y por supuesto, una danza muy particular que se realiza en mi pueblo: la danza de los Moros, también conocida como "Baile de los Chavaricos". Esta contradanza es bailada a ritmo de chirimía y tambor, y durante su ejecución (en la Semana Santa y en diciembre, el día de Santa Lucía) los Moros y los Cristianos (con máscaras y capas) combaten recitando cantares de gesta, principalmente, el Cantar de Roldán. Así, los niños escuchábamos esos versos y los aprendíamos de memoria, incluso algunas veces, modificándolos. A la par de esto, uno de los primeros libros que leí fue la Biblia, por lo que su poesía también me influyó. Sin embargo, fue hasta mi ingreso a la universidad, en la Biblioteca Central de la Ciudad Universitaria de la UNAM, en la Ciudad de México, hacia 1996, cuando comencé a leer libros de poesía de forma sistemática. A partir de ahí, no he dejado de leer poesía y, hacia mediados de 2003, comencé a escribirla y aún sigo trabajando en ello.

\section{¿Con que obstáculos se encontró usted al momento de tratar de incursionar en el mundo de las letras en su país?}

Principalmente con las grandes murallas de ego de varios de los primeros escritores que conocí, ya que muchos "poetas" están más preocupados en erigir un culto a su propia personalidad, a su "carrera artística", que en construir una obra, es decir, tienen una gran sed de reconocimiento a su persona, en lugar de enfocarse en construir y escribir obras para la posteridad. Y no estoy en contra de la fama y el prestigio, pero éstos deben ser secundarios, derivados de una obra de arte reconocible y duradera. Afortunadamente, desde el principio me han interesado más (y me siguen interesando) las distintas manifestaciones del arte, que los artistas que las crean. Sobre todo, aquellos poetas que manifiestan una honda condición humana en lo que escriben. Otro obstáculo es que nuestra sociedad, y aún nuestra propia familia, difícilmente reconoce a la poesía como un oficio, como una profesión, y al poeta como un trabajador de la palabra, un oficiante del lenguaje que aspira a vivir digna y honestamente de lo que hace, por lo que su trabajo debe ser remunerado materialmente. Aún hoy en día, para muchas personas, el oficio de poeta es visto como una actividad de ocio, una suerte de divertimento, algo ocasional y vago, en lugar de verse como una vocación, una singular forma de ganarse la vida. He de confesar, sin embargo, que no me interesa incursionar en el "mundo de las letras", sino en crear una obra, al menos un verso, que sobreviva al paso del tiempo.

\section{Háblenos de sus talleres de lectura, por favor.}

No he asistido a talleres de lectura o de poesía, más que en forma ocasional. Por ejemplo, el poeta chiapaneco Máximo Cerdio dirigía el taller literario iniciado por el poeta Óscar Oliva en la Casa de la Cultura "Jesús Reyes Heroles" en Coyoacán, Ciudad de México, y algunas veces lo visitaba, sobre todo, para platicar con él de las cosas de Chiapas y compartir una taza de café con otros amigos en común que asistían al taller con regularidad. En realidad, los libros de poesía han sido para mí esos talleres vivos en los cuales he aprendido lo poco que sé sobre poesía. Por otra parte, cuando fui becario del programa Jóvenes 
Creadores del FONCA tuve como tutores a los poetas Francisco Segovia y Mario Bojórquez, y tanto ellos como mis compañeros Iván Cruz, Eduardo Saravia, Audomaro Ernesto, Reneé Acosta y Carlos Adolfo Gutiérrez Vidal me aportaron mucho en las reuniones de trabajo trimestrales, ya que por primera vez pude "tallerear" uno de mis libros de poesía y estar sujeto a la crítica y opinión de los demás. Esa fue una muy buena experiencia, y no quiero olvidar a los poetas Eduardo Hidalgo y Roberto Rico que fueron tutores míos cuando tuve otras becas en Chiapas, pues ellos me orientaron y aportaron mucho con su experiencia y lecturas.

\section{Además de poesía usted ha escrito ensayos, cuentos, crónica y temas de interés científico. ¿Nos podría citar alguno de ellos?}

Citaría el ensayo que lleva por título "Vegetalidad en la poesía de Eduardo Lizalde: fitonimias, fitofilias y fitofobias a partir de una lectura otra del Manual de flora fantástica" (publicado en el libro colectivo Una raya más. Ensayos sobre Eduardo Lizalde. México: Fondo Editorial Tierra Adentro, 2010, coordinado por el escritor chiapaneco Víctor Cabrera). Dicho ensayo es una aproximación ecocrítica y ecopoética, así como una mirada desde la literatura fantástica, a uno de los libros más singulares Eduardo Lizalde, al que considero el poeta mexicano vivo más importante. En ese texto pongo en conjunción, y al servicio del ensayo, dos de mis grandes pasiones: la botánica y la poesía. Creo que la ciencia y la poesía están estrechamente vinculadas, pues existe, así lo creo, una correlación entre la metáfora y la hipótesis científica.

\section{Tiene usted en su haber una larga lista de premios y reconocimientos, todos por demás importantes} ¿Existe alguno entre ellos que tenga un significado especial para usted?

Todos los premios que ha recibido mi obra son importantes para mí, aunque considero que el Premio Estatal de Poesía Raúl Garduño 2004 (el primer premio que obtuve), así como el Premio de Poesía Joven Ciudad de México 2006, el Certamen Internacional de Literatura Sor Juana Inés de la Cruz 2012 y el Premio Internacional de Poesía Jaime Sabines 2014, son los más significativos y emotivos, tanto por el prestigio derivado, como por el momento en el que éstos reconocimientos llegaron a mi vida y a la de mi familia.

\section{Se le describe como un "poeta de semblante recio y voz potente", que habla, denuncia, y critica sin} rodeos. ¿No le teme a las represalias?

En México, dada la situación de inseguridad, impunidad, violencia e injusticia, claro que uno teme a las posibles represalias al mantener una postura ética, una visión crítica y denunciar, aunque sea por medio de la poesía como instrumento, las diversas injusticias que a diario se cometen en el país. Sin embargo, no

podemos vivir con miedo todo el tiempo, y tengo un compromiso ético y estético conmigo mismo y con los demás, de ahí la necesidad de hacer valer mi postura, y hacerla pública, toda vez que algunas veces tengo la oportunidad de manifestarla ante los medios de información, y aun cuando sea contraria a la establecida por el poder en turno. 
Usted dice que "el poeta debe estar comprometido con las causas justas" y convertirse en un "ciudadano de calle" para lograr un cambio. ¿Cree usted que lo está logrando?

Yo no podría decir si lo estoy logrando o no, pero al menos intento no mantener una actitud de indiferencia o servil y adocenada frente a la injusticia o los poderosos. Por el contrario, creo que el artista, el poeta, como ciudadano, como ser humano común, debe cambiar, primero, él mismo, y en ese sentido, a través de su obra, y de una coherencia entre lo que hace-escribe y lo que vive- dice, es decir, entre su palabra y su acción, proponer un cambio. No podemos exigir que los demás cambien si nosotros no lo hacemos. Lamentablemente, las personas pocas veces escuchan a los poetas, quizá porque estos últimos están tan ensimismados en su esfera personal, en su esfera íntima y literaria que poco tienen que decir, con su poesía, a los demás. Pero no debemos bajar los brazos, ya que nuestra tarea, aunque difícil y utópica, es necesaria: creo que la poesía, la verdadera poesía, nos refleja en el espejo de lo humano, nos rehumaniza.

"Así que las palabras representan las voces, y las voces significan, como dice Aristóteles, los pensamientos que tenemos en el ánima”. ¿Es usted esa voz del pueblo que clama justicia?

Posiblemente mi voz no sea la voz del pueblo, ya que no siempre "clamo" por justicia en mi poesía, en mis poemas. Pero en la medida en que mis poemas toman las palabras del pueblo, sus vocablos, su forma de hablar y pensar, e intento integrarlas y transformarlas en poesía, creo que de algún modo le doy voz, ya que me debo al pueblo y soy reflejo individual de un ente colectivo y múltiple: su lenguaje. Y así, cada vez que intento hallar y emplear la palabra justa en cada uno de mis poemas, que a su vez están llenos de muchas de las palabras que el pueblo utiliza todos los días, le hago, quizá, un poco de justicia, pero una justicia por demás y únicamente poética.

\section{¿Podría ser usted el Caronte que transporte las almas de toda una nación hacia aguas menos turbulen-} tas y consiga la paz a través de su literatura?

Lamentablemente no soy una suerte de guía hacia un estado de armonía o mensajero alguno de la paz. Al respecto, el gran poeta chileno Jorge Teillier escribió lo siguiente: "Ninguna poesía ha calmado el hambre o remediado una injusticia social, pero su belleza puede ayudar a sobrevivir contra todas las miserias". De este modo, lo único que intento, con mi poesía, con mi trabajo, es hacer que los otros se reflejen en mis poemas como en un espejo, y que este espejo refleje la honda condición humana: la luz o el abismo, la miseria o lo inefable. Lo he dicho muchas veces: sólo intento, con mi poesía, hacer más habitable este mundo.

Es usted parte de la llamada “Generación del 94". ¿Qué es lo que caracteriza a este grupo de jóvenes escritores?

Es un término que yo mismo concebí y manifesté el año pasado en una entrevista para el diario electrónico "Chiapas Paralelo", aunque entonces no lo definí del todo (y tampoco me extenderé aquí), ya que forma parte de un ensayo sobre poesía y poetas de Chiapas que tengo inédito. He llamado así, "Generación del 94", a todos aquellos poetas chiapanecos que comenzaron a escribir y publicar su obra, sus primeros libros 
de poesía importantes, después del alzamiento del Ejército Zapatista de Liberación Nacional, el movimiento insurgente y guerrillero de 1994 que dio un giro decisivo y relevante a la forma en la que Chiapas era visto por los mexicanos, y claro, por los chiapanecos. A partir del surgimiento del EZLN, Chiapas no volvió a ser el mismo, y tampoco sus poetas, aunque algunos de ellos siguen teniendo los mismos vicios decimonónicos: conciencia de pertenencia a una casta o clase social especial (alta, por supuesto), una conciencia y un actuar "ladinos" (me refiero a un supuesto linaje y origen familiar de cierto abolengo, un pensamiento claramente colonial, castizo), subordinación al poder político en turno, así como formar parte de la élite que ostenta el poder y la oligarquía reinante, e incluso, ser uno de los caciques políticos, culturales, etc. Así, los poetas que forman parte de la que he llamado "Generación del 94" no son "ladinos", ni tienen linaje entre los poderosos y no forman parte de la élite ni ostentan poder político o caciquil alguno, muy por el contrario, nacieron "sin linaje", mantienen una constante crítica hacia el statu quo, contra el establishment, y su obra refleja, directa o indirectamente, su posición, tanto ética como estética. Pero no necesariamente los poetas de la "Generación del 94" nacieron en la misma década o escriben una poesía de contenido social, contestatario o comprometido. Lo que quiero destacar es que su obra comenzó a gestarse después del levantamiento zapatista, y crecieron en un Chiapas distinto, con una aspiración a mayor igualdad étnica y social, y ya no importó para ellos crecer bajo las faldas de algún poderoso o nacer cobijado por un apellido o familia de "casta", y su quehacer estético, sus principales libros, han sido escritos con plena conciencia crítica e incluso al margen del poder, y en algunos casos, lejos de Chiapas. Los poetas de la "Generación del 94" nacieron principalmente en la década de los años setenta y ochenta del siglo pasado, pero algunos también en la década de los años sesenta. Mencionaré a algunos de ellos: Máximo Cerdio, Eduardo Hidalgo, Juan Carlos Bautista, Marco Fonz, Armando Sánchez (poeta maya tseltal), de la década de los sesenta; Ulises Córdova, Víctor Cabrera, Luis Arturo Guichard, Víctor García Vázquez, Víctor Avendaño Porras, Ignacio RuizPérez, Ruperta Bautista (poeta maya tsotsil) de los setenta; Raúl Vázquez, René Morales, Ameht Rivera, Mikeas Sánchez (poeta zoque), Fabián Rivera, Manuel López y Luis López (poetas maya tsotsiles), Rodolfo Girón, Daniel López García, Jorge Chaleco, Felipe Flores Gálvez, Miguel Ángel Guzmán, de los ochenta, entre otros.

\section{Hablemos de sus poemas [ eternometraje montado en daguerrotipos sobre las calles de una ciudad en deconstrucción ] y [ esbozo de un poema apócrifo escrito en papel de estraza entre frontera \#158, colonia roma, y una fonda de caldos en la colonia doctores, año de Dios del dos mil dos o dos mil tres ]. ¿Cómo nacen esos textos?}

Ambos poemas surgen de mi encuentro, en principio beligerante, pero luego amoroso, con la urbe, con la Ciudad de México, lugar en el que viví un par de décadas. Esos textos pertenecen a mi libro Icarías, que escribí mientras realizaba largos paseos montado en bicicleta por el sur de la urbe, sobre todo, dentro de la Ciudad Universitaria de la Universidad Nacional Autónoma de México y sus alrededores. Sin embargo, la "conciencia" de escritura de ese libro ya la había desarrollado, es decir, había concebido tiempo antes esa "idea de libro". El detonador fue montarme de nuevo en una bicicleta, luego de varios años de no poder hacerlo debido a una lesión en la rodilla izquierda. De hecho, una primera versión de "[esbozo de un poema apócrifo...]" la escribí -literalmente- sobre una bolsa para guardar pan hecha de papel de 
estraza (posiblemente en el 2003) y retomé el poema en el 2007, cuando escribí Icarías completo. Así, mientras manejaba la bicicleta, iba "construyendo" y "deconstruyendo" los poemas en mi cabeza, luego me estacionaba en algún cibercafé y los enviaba a mi dirección de correo electrónico o me detenía a escribir en mi libreta los fragmentos que no escapaban a la memoria. En cuanto terminé de "vaciar" al papel los poemas (en sólo un par de días), me di a la tarea de darle forma al libro, eliminando aquellos fragmentos que no consideré reflejaran mi búsqueda: Icarías quedó terminado en una semana, no más.

"sangre que fluye apenas coagulada desde solitarios y frescos cadáveres, porque en la muerte nadie nos acompaña", "porque inmensa es la ciudad y abandonada y herrumbrada como los ocres páramos que extraño, fríos y violentos y también inmaculados porque en esta urbe no hay siquiera una astilla de pureza". ¿Es este el México de hoy?

Es, en el caso de este poema, un ejercicio desde la conciencia de un hombre ajeno a la urbe, a la gran Ciudad de México (donde la muerte del otro es cotidiana y pasmosamente desapercibida), un hombre que extraña la provincia perdida, pero con el tiempo ha devenido tanto en una suerte de flâneur gozoso que degusta y disfruta estéticamente los excesos y el anonimato que le da la ciudad, así como en un voyeur urbano que encuentra placer estético en deconstruir y construir verbal e imaginariamente a la ciudad, por ello la lee y relee, como si fuese un palimpsesto interminable o un lienzo cambiante sobre el que deja sólo la huella de sus lecturas, borrones y pastiches: una de ellas, él mismo. Eso es parte de lo que buscaba en aquellos poemas, en aquel Icarías, que en ningún modo pretendía vaticinar el horror que se vivía y se vive en México por la violencia.

¿En sus poemas existen elementos que se mencionan constantemente y que parecen articular un lenguaje simbólico, casi cifrado? ¿Cuál es la función de esos símbolos?

Quiero mencionar, por ejemplo, y entre otros símbolos, la constante presencia de los ángeles en algunos de mis libros, aunque también podría mencionar la lengua (el órgano), así como el mar, y en mis últimos libros, el machete. Tales símbolos son tanto una proyección sicológica de mis intereses y preocupaciones personales, como elementos que utilizo con plena conciencia, dada la función que deben cumplir en los textos. En el caso del ángel o los ángeles en mis poemas, son figuras importantes en cuanto a la revelación de un mensaje, tal como aparecen, por ejemplo, en la Biblia. De este modo, creo que el poeta debe ser como un ángel que revele, al menos, una idea, quizá su propia idea del mundo, no necesariamente un mensaje celestial o ininteligible para los no elegidos, sino que el poema revele al otro su condición humana. Por otro lado, en mi poesía última el machete es un símbolo muy presente, pues creo que es el instrumento con el que los hombres de Centroamérica y, por ende, de Chiapas, hemos intentado domesticar nuestro entorno y darle forma; con el machete los hombres del trópico escribimos sobre la tierra nuestro mensaje, y no con la pluma o la espada como en Occidente. Y siendo el machete una burda herramienta de trabajo del hombre de campo (es decir, el que habita la selva o el bosque latinoamericano), así como un instrumento de defensa o arma de guerra del mismo hombre (ya que su economía le impide hacerse de otro tipo de armas, por ejemplo, las de fuego) esa ambigüedad representa, para mí, una metáfora del espíritu y de la condición 
centroamericana, de nuestra identidad: el machete ha escrito nuestro pasado, escribe nuestro presente y posiblemente escribirá nuestro futuro, ya que no nos alcanza para más. De ahí el carácter enmarañado, agreste, complejo, contradictorio y paradójico de los habitantes de esta parte del mundo donde aún reinan eternos e ignorantes caciques coronados por reinas de juegos florales y que blanden machetes, los de la violencia, como forma de "diálogo". El machete es una metáfora del lenguaje, del hombre cerrero, rústico, incivilizado, que es el reflejo de la sociedad agrícola centroamericana, mayormente campesina, a la que hicieron entrar por la fuerza (de las armas, de la violencia, del abandono, del horror) en la posmodernidad y que no tiene más que la misma y única herramienta para defender su espacio vital, para descifrar su entorno y seguir escribiendo su cosmovisión: el machete. Y nosotros los centroamericanos lo seguimos utilizando para limpiar de malezas la milpa, para sembrar, para borrar, y aún más, para escribir poesía.

\section{Braille para sordos es impactante. En ese libro hay imágenes, palabras que traspasan almas, despiertan conciencias y nos obligan a mirar con el corazón. ¿Cómo logra usted esa conexión con el lector?}

Es un libro pensado y escrito desde una conciencia estética distinta, cavilada desde y hacia otra dirección poética en relación con otros libros míos. Desde el título y hasta el último poema, Braille para sordos está pensado como una "totalidad fragmentaria", una obra de arte que puede ser leída y "sentida" en varios niveles de lectura. La idea primera de este libro surge de mi contacto con la fotografía, con el arte de dos de los primeros fotógrafos de la historia, Joseph Nicéphore Niépce y Louis Jacques Mandé Daguerre, la obra plástica de Max Ernest y Joseph Cornell, y las impactantes fotografías de Diane Arbus. Lo que intento en este libro es crear/hacer una cajita craquelada, a la manera de Cornell, hecha con elementos poéticos en apariencia disímiles, para construir objetos verbales en conjunción con ciertas imágenes que, espero, potencian aún más el sentido original tanto de las palabras como de las imágenes en juego. Escribí el libro pensando en los lectores comunes de poesía y en los lectores legos de siempre, y a todo lector insospechado a quien va dirigido este poemario, para que leyeran poesía/ fotografía/objetos de arte desde el envés del espejo de la página, y no desde el "as" de su común superficie. Por ejemplo, casi todas las fotografías, esculturas, pinturas y otras obras de arte expuestas en galerías y museos llevan una "ficha técnica" muy breve que los acompaña, o cuando menos, tienen la firma del autor, las dimensiones, el precio, etc., que muestran cierta relación de la palabra con la imagen/objeto creado. Sin embargo, lo que intentan ser buena parte de los poemas de Braille para sordos es una especie de "fichas técnicas" o "notas al pie" muy largas, y de vocación poética que intentan dar al lector/veedor algo más que sólo información técnica sobre un objeto de arte: le proponen mirar con el corazón, mirar el arte con los ojos vendados de poesía. Y los lectores tienen la última palabra, vaya, el tiempo dirá si este libro (que no propone nada nuevo, ya que otros escritores han creado libros similares) logra acercarlos, de un modo otro, al hecho poético, al arte y, fundamentalmente, a la poesía.

Tuve la oportunidad de leer algunos de sus poemas, en ellos existen cierta ambigüedad entre la palabra poética y la palabra sagrada, lo espiritual, entre poesía y revelación. ¿Qué puede decir al respecto?

Tiene que ver, quizá, con el hecho de que soy creyente cristiano -evangélico-confeso, y en ocasiones 
llevo muchas de mis tribulaciones y preguntas existenciales a la poesía. Así, en lugar de "elevar" un sordo monólogo a Dios en la oración (como cualquier creyente cristiano), creo que la poesía me permite hacer colectivas y múltiples dichas aflicciones, sobre todo las de orden espiritual. Si bien ciertos hombres reciben revelaciones directamente del Dios cristiano (lo que creo con firmeza), y las comunican a otros hombres, muchas de esas revelaciones se limitan a un espacio religioso o sagrado determinado, limitado por la liturgia, la religiosidad y que no puede prescindir de ciertos dogmas inalterables, mientras que la poesía (así lo creo y tengo fe en ello) acerca a cualquier hombre a una experiencia de tipo espiritual, es decir, a la espiritualidad, sin necesidad de que el hombre que hace poesía y el que la lee tengan la misma religión, y sin dogma absoluto o ritual alguno. Muy por el contrario: la poesía es capaz de prescindir de su perfil religioso, no así de su honda espiritualidad, claro, siempre que sea verdaderamente poesía. En eso también tengo fe: en que los hombres pueden hermanarse más por la poesía que por la religión.

\section{Recientemente, en diciembre del 2014, usted ganó el Premio Internacional de Poesía Jaime Sabines por su libro Iceberg negro. ¿Qué tiene de particular este libro?}

Es un libro en el que vierto muchas de mis tribulaciones espirituales como cristiano intento transformarlas en poesía, pero desde una perspectiva evangélica/protestante; sin embargo, intento lograr cierta mística (aclaro lo anterior ya que casi toda la poesía religiosa cristiana es de origen o vocación católica). Pero contrario a lo que parezca, no intento predicar, ni convertir, ni difundir ni acercar a la fe cristiana (a mi fe) a nadie en absoluto. Iceberg negro es antes poesía y después, así lo espero, poesía: tal es su "doctrina” lírica.

\section{Usted se refiere a Iceberg negro como un libro "de desaliento luminoso". ¿A qué se refiere con esto?}

Dije esto en una entrevista porque en ese libro quise escribir un largo poema, dividido en varias secciones, con el mismo aliento de Job, y reflejar así mi propio desamparo y orfandad existencial, para escribirlo en la niebla cotidiana de la vida y desde las profundidades del abismo del alma. Tomé como ejemplo el Libro del Job bíblico, en el entendido de que los creyentes cristianos no tenemos porqué estar en la mejor posición, ni tener todas las bendiciones del mundo para amar a Dios. Por paradójico que parezca, la tarea del hombre (cristiano) es amar a Dios a pesar de que Él ni siquiera lo escuche o responda a sus ruegos. Y por doloroso que parezca, el cristiano no debe esperar "recompensas" de su Dios, pues Él no promete felicidad alguna durante nuestro breve paso por la tierra. El creyente cristiano de fe verdadera debe seguir su camino, el camino del Amor a Dios (el Ágape, totalmente incondicional) y al prójimo, aunque esté en el más completo desamparo y abandono, aunque Dios mismo no responda a sus ruegos y plegarias. De esa dimensión es la tarea enorme del cristiano que debe esperar después de la muerte, quizá, para recibir su recompensa.

\section{¿Por qué usar un seudónimo para este libro cuando se cuenta con una larga y exitosa trayectoria?}

Lo utilicé porque en el caso del certamen "Premio Internacional de Poesía Jaime Sabines" una de sus cláusulas de participación indicaba que era necesario utilizar un seudónimo; esto, para hacer más objetiva

e imparcial la labor del jurado al elegir el libro que ellos consideraron ganador. Sin embargo, el libro será 
publicado con mi nombre de escritor, Balam Rodrigo.

\section{¿Por qué usar como seudónimo la locución latina "Nihil Sine Deo" ("Nada sin Dios")?}

Porque todo lo que hago y soy se lo debo a Dios, y nada está fuera de Él. Es una declaración de fe, de mi fe como cristiano evangélico.

\section{¿Por qué dice usted que al escribir Iceberg negro está "en paz con Dios"?}

El libro lo escribí poco después de casarme, y en ese año (2007), tenía serios conflictos espirituales, pues no sabía si dedicarme de lleno a una posible carrera pastoral (al ministerio cristiano) o tomar de lleno y ciegamente las riendas de esa cuadriga desbocada por los caballos salvajes de la poesía. Finalmente me decidí por la poesía y abandoné, poco a poco, mis vínculos dentro de la congregación a la que pertenecía, lo que me permitió respirar como librepensador, sin más ataduras que las espirituales y una fe sin religiosidad dogmática. Tomar esa decisión, por ilógico que parezca, me puso en paz con Dios y conmigo mismo.

\section{¿Cree usted que pudiera existir una relación entre la revelación poética y su nombre de autor?}

No lo creo, pero mis nombres sí tienen un origen literario. Mi primer nombre, Balam, lo eligió mi padre a partir de su lectura del Popol Vuh (en la versión de Adrián Recinos), ya que el primer hombre de maíz (según la cosmovisión maya quiché sobre el origen del mundo plasmada en ese libro) recibió el nombre de Balam Quitzé por parte de las deidades. Y así iba a llamarme, pero mi madre exigió a mi padre su "colaboración" en la elección de mi(s) nombre(s), y en lugar de Quitzé como segundo epíteto, se decidió por Rodrigo, ya que cuando era niña leyó el Cantar de Mio Cid, y tanto la maravilló ese poema épico (en particular las hazañas del Cid Campeador, don Rodrigo Díaz de Vivar), que se prometió ponerle ese nombre, Rodrigo, a su primer hijo varón. De niño, al enterarme del porqué de mi nombre, sentí una enorme curiosidad, por lo que leí ambos libros. Esto también me llevó a pensar, como a cualquier otro latinoamericano interesado en sus orígenes, en que nos debemos a un profundo y rico mestizaje que da forma y sentido a quienes somos.

\section{¿Cuáles son sus proyectos literarios para este año?}

De entrada, verán luz los siguientes libros de poesía: Libro de sal (Posdata, Colección Lágrima de Batavia, México, 280 p., 2013) -en la página legal tiene ese año de edición, pero fue publicado este año-, Desmemoria del rey sonámbulo (Secretaría de Cultura de Guerrero, México, 104 p., 2015), El corazón es una jaula de relámpagos (antología poética 2005-2015) (E1 Gallo de Oro Ediciones, España, 2015), El órgano inextirpable del sueño (antología poética 2005-2015) (Metáfora Editores, Guatemala, 2015), Oficios del neólogo (Lempa, Colección de Poesía Centroamericana, Chile, 2015), Iceberg negro (Coneculta-Chiapas/Ediciones Atrasalante, 2015) y la plaquette Silbar de mirlos para la hermusa (2015) que verá luz en San Luis Potosí, México. Asimismo, me encuentro escribiendo un libro de ensayo en el que reflexiono en torno a la poesía de la frontera sur de México, así como el carácter e identidad plenamente centroamericanos de la poesía de Chiapas. Con esto 
quiero decir, entre otras cosas, que los mexicanos que nacimos en Chiapas somos tan centroamericanos como los otros centroamericanos que habitan desde Guatemala hasta Panamá (o viceversa). Será este 2015 en definitiva, y gracias a Dios, un año de muchas bendiciones de orden vital y literario. 